\title{
Processos de comunicação de inicio de fabricação de produtos dispensados de registro em vigilância sanitária de Uberlândia
}

\section{Katiuce Aparecida de Oliveira ${ }^{1}$, Fernanda Barbosa Borges Jardim ${ }^{2}$, Eliane Cristina Lombardi ${ }^{3}$ e Ricardo Tomaz da Silva ${ }^{4}$}

Os produtos de competência de fiscalização da Agência Nacional de Vigilância Sanitária são divididos em duas categorias: produtos com registro obrigatório e produtos dispensados de registro, sendo que o último passou a ser de responsabilidade do município. Observa-se que as empresas possuem dificuldades na aprovação da comunicação de início de fabricação de produtos dispensados de registro, que demanda o preenchimento de formulários e apresentação de documentos próprios das empresas, como alvará sanitário. Este estudo teve por objetivo avaliar as não conformidades encontradas nos processos de produtos dispensados de registro protocolados na Vigilância Sanitária de Uberlândia, MG. O método de estudo foi o descritivo, com a quantificação das não conformidades nos processos protocolados pelas empresas para comunicação de início de fabricação de produtos dispensados de registro, que exigem a entrega de documentos da empresa, preenchimento de um formulário (Anexo X)e apresentação dos modelos de rótulos dos produtos. No total de 169 processos avaliados entre 2012 e 2016, apenas quatro (2,37\%) conseguiram aprovação. Nos demais, constatou-seerros, especialmente nos rótulos $(97,6 \%)$. Houve inconformidades também na apresentação da documentação pertinente ao processo $(35,5 \%)$ e no preenchimento do formulário $(65,5 \%)$. Pôde-se observar que o índice de inconformidades nos processos foi expressivo, sendo necessárias ações educativas por parte do órgão fiscalizador para sensibilização das empresas e capacitação das mesmas com o intuito de melhorar os índices de aprovação dos processos de produtos dispensados de registro.

Palavras-chave: Alimentos; Registro; Rotulagem; Vigilância Sanitária.

\section{Procedures for products that are exempt from registrationin health surveillance of Uberlândia}

Products under the supervision of the Brazilian Health Regulatory Agency (Anvisa) are divided into two categories: mandatory registration products and products that are exempt from registration, the last one is under the Cities' responsibility. It was observed that the companies are having difficulties to elaborate and present the necessary documents in order to obtain approval in the Registration's Exempt Products Manufacture Start report, which requires form fillings and document's presentation such as Sanitary Licenses. This study's objective was to evaluate the unconformities found in the processes protocoled at Uberlândia's Health Surveillance Office. The study's method was descriptive, quantified the number of assessed processes and the document's unconformities such as form fill-in errors and label's irregularities. One hundred sixty-nine processes were assessed between 2012 and

\footnotetext{
${ }^{1}$ Mestre em Ciência e tecnologia de alimentos. Instituto Federal de Educação, Ciência e Tecnologia do Triângulo Mineiro, Uberaba - MG. Endereço para correspondência: Rua das Paineira, 995 ap 402 b 6 - Uberlândia (MG); Tel.: (34)99130-0615. E-mail: katiuceapo@hotmail.com.

2 Doutora em alimentos e nutrição. Instituto Federal de Educação, Ciência e Tecnologia do Triângulo Mineiro, Uberaba - MG; fernanda.jardim@iftm.edu.br.

3 Mestre em Ciência e tecnologia de alimentos. Instituto Federal de Educação, Ciência e Tecnologia do Triângulo Mineiro, Uberaba - MG. elianecl@gmail.com

${ }_{4}^{4}$ Doutorando em ciências veterinárias. Universidade Federal de Uberlândia. ricardovet@hotmail.com
} 
2016. Only 4 (2.37\%) were approved. In the others errors were detected, especially on labels (97.6\%). There were also unconformities at relevant document's presentation $(35.5 \%)$ and form fill-in errors $(65.5 \%)$. In conclusion, it was observed that the unconformities index was significant, which reflected the necessity of the surveillance body to offer training and educational actions regarding the subject to the companies.

Keywords: Food; Registry; Labeling; Health surveillance

\section{INTRODUÇÃO}

Para desburocratização dos processos de regularização dos produtos alimentícios de sua competência, a Agência Nacional de Vigilância Sanitária (ANVISA), por meio da RDC n²3/2000, dividiu os produtos em dois grupos: alimentos com registro obrigatório (São produtos que podem apresentar riscos maiores em seu consumo e por isso devem passar por avaliação na ANVISA antes do início de sua comercialização, por exemplo produtos probióticos) e os alimentos dispensados da obrigatoriedade de registro (produtos com menor risco a saúde da população, como por exemplo, o pão de queijo congelado). Para os produtos dispensados da obrigatoriedade de registro, a empresa deve somente informar o início da fabricação ao órgão de vigilância sanitária podendo dar início imediato à comercialização $^{[1]}$.

Como parte da comunicação de início de fabricação de produtos dispensados de registro, a Vigilância Sanitária Municipal de Uberlândia instituiu a necessidade das empresas apresentarem os seguintes documentos: cópia do alvará sanitário vigente da empresa produtora do alimento e da empresa fornecedora da embalagem; formulário de comunicação de início de fabricação de produtos dispensados de registro e de embalagem (formulário anexo $\mathrm{X}$ ); ficha técnica da embalagem; modelos dos rótulos dos produtos comunicados. Esta forma de comunicação é realizada somente no município de Uberlândia como forma de regulamentação e fiscalização dos rótulos comercializados ${ }^{[2]}$.
Apesar da existência de material explicativo no site da Prefeitura de Uberlândia e ANVISA, de como preencher corretamente esta documentação, muitas empresas têm dificuldades de preencher corretamente os formulários (deixando até campos importantes sem preenchimento) e deixam de apresentar alguns documentos. Além disso, a rotulagem dos produtos tem sido um ponto crítico, que tem causado inúmeras devoluções de processos por apresentar itens não conformes segundo legislações que regulamentam a rotulagem.

Mesmo com o apontamento das não conformidades sendo realizado através de pareceres técnicos emitidos por meio da análise dos processos, muitas empresas possuem dificuldades de corrigir esses formulários e rótulos, pois desconhecem a legislação relacionada a rotulagem. Isso provoca um congestionamento de processos não aprovados, que retornam várias vezes sem a devida correção.

Conforme previsto na RDC $\mathrm{n}^{\circ}$ $23 / 2000$, as empresas que não possuem a aprovação do processo de anexo $\mathrm{X}$ de seus produtos perante a vigilância sanitária, a mesma pode ser notificada a suspender a produção dos produtos e/ou o recolhimento de seus produtos no mercado (com divulgação para notificação). Podem ser aplicadas também outras penalidades previstas em lei (interdição, autuação, apreensão e inutilização) ${ }^{[3]}$.

Em um estudo feito na cidade de Curitiba, PR, sobre os dizeres da rotulagem dos produtos dispensados de registro fabricados no 
município, foram analisados 2.425 rótulos. Houve uma melhora significativa na adequação das rotulagens (disposição das informações, dizeres de acordo com a realidade do produto). As empresas receberam orientações por parte da Vigilância Sanitária durante os trabalhos de adequação dos rótulos, o que contribui para os resultados positivos ${ }^{[4]}$.

O diagnóstico dos processos protocolados na Vigilância Sanitária de Uberlândia para conhecer os principais entraves que não permitem um fluxo ideal e conclusão efetiva dos processos é pertinente e possui impacto social e econômico. As empresas necessitam que seus processos produtivos sejam legalizados para que possam exercer suas atividades econômicas e a sociedade deve ter assegurado o direito de informação, assegurado pelo Código de Defesa do Consumidor ${ }^{[5]}$. Os alimentos comercializados devem ser oriundos de empresas credenciadas junto aos órgãos sanitários, sendo uma garantia de que seus rótulos foram revisados e aprovados pelo órgão sanitário conforme a legislação pertinente.

O objetivo deste estudo foi fazer um levantamento dos processos de comunicação de início de fabricação de produtos dispensados de registro recebidos e analisados nos anos de 2012 a 2016 pela Vigilância Sanitária do município de Uberlândia, MG, e discutir as principais não conformidades observadas nos documentos.

\section{MATERIAL E MÉTODOS}

O levantamento dos dados dos pareceres dos processos de anexo $\mathrm{X}$ protocolados de 2012 a 2016 foi realizado entre os meses de outubro de 2016 a fevereiro de 2017, na unidade de Vigilância Sanitária do município de Uberlândia, MG, no setor de arquivo. Antes do início da pesquisa, a mesma foi aprovada pelo setor de estudo e pesquisa da Prefeitura Municipal de Uberlândia. A estratégia metodológica adotada foi o estudo descritivo, de modo que foram quantificados os processos e investigadas as principais não conformidades nos documentos.

Foram verificados os documentos não apresentados no processo, no preenchimento do formulário de início de fabricação dos produtos dispensados de registro (formulário de anexo X) e na rotulagem dos produtos.

$\mathrm{Na}$ verificação da documentação, foi investigado se os processos apresentavam os documentos: formulário de comunicação de início de fabricação dos produtos dispensados de registro devidamente preenchido e com visto da vigilância sanitária local de origem da indústria, cópia do alvará sanitário vigente, rótulos de todos os produtos comunicados, cópia do alvará sanitário do fabricante da embalagem e ficha técnica da embalagem.

$\mathrm{Na}$ análise do preenchimento do formulário de anexo $\mathrm{X}^{[3]}$, foram avaliados os erros mais comuns nos campos de categoria e descrição da categoria, nome do produto, marca do produto, tipo de embalagem, validade, controle/numeração dos anexos, dados do detentor do produto/marca, dados da unidade fabril, termo de responsabilidade e perspectiva comercial. Também, foi verificado se o formulário foi apresentado com a formatação exigida pela RDC n²3/2000 ${ }^{[3]}$.

Para avaliação dos rótulos, foram avaliados os seguintes itens: denominação de venda; lista de ingredientes; declaração de aditivos na lista de ingredientes; conteúdo líquido; identificação de origem; identificação do lote; prazo de validade; condições especiais para sua conservação; preparo e instrução de uso; apresentação e distribuição da informação obrigatória; aditivos intencionais e coadjuvantes de tecnologia (quando houver) ${ }^{[6]}$; declaração de $\operatorname{alergênicos}^{[7]}$ e alimentos que causam intolerâncias $^{[8]}$ (quando houver); rotulagem nutricional ${ }^{[9]}$; alimentos para fins especiais ${ }^{[10]}$ 
(quando aplicável); declarações especiais de suplementos $^{[11]}$ (quando aplicável); declarações de suplementos vitamínicos e/ou minerais (quando aplicável); declaração de presença de Organismos Geneticamente Modificados ${ }^{[12]}$ (quando houver); informações obrigatórias para compostos líquidos prontos para o consumo ${ }^{[13]}$ (quando aplicável) e informações obrigatórias para cereais ${ }^{[14,15]}$ (quando aplicável).

Os dados foram tabulados em planilhas com auxílio do programa Excel 2013, por meio da quantificação de erros presentes no processo e os resultados foram apresentados em forma de gráficos.

\section{RESULTADOS E DISCUSSÃO}

A relação dos processos recebidos, analisados e aprovados pela Vigilância Sanitária pode ser visualizada na Figura 1.

Tabela 1. Número de processos recebidos, analisados e aprovados de processos de anexo $\mathrm{X}$ protocolados pelas empresas na Vigilância Sanitária de Uberlândia, MG, nos anos de 2012 a 2016.

\begin{tabular}{|c|c|c|c|c|c|c|}
\hline \multirow{2}{*}{$\begin{array}{c}\text { Processos } \\
\text { Anos }\end{array}$} & \multicolumn{6}{|c|}{ Quantidade (no $)$} \\
\hline & 2012 & 2013 & 2014 & 2015 & 2016 & Total \\
\hline Recebidos & 82 & 63 & 47 & 42 & 57 & $\begin{array}{c}291 \\
(100 \%)\end{array}$ \\
\hline Analisados & 23 & 40 & 26 & 9 & 71 & $\begin{array}{c}169 \\
(58,07 \%)\end{array}$ \\
\hline Aprovados & 1 & 1 & 2 & 0 & 0 & $\begin{array}{c}4 \\
(1,34 \%) \\
\end{array}$ \\
\hline
\end{tabular}

Conforme demonstrado na Figura 1, a média de processos recebidos nos anos de 2012 a 2016 foi de aproximadamente 58 processos/ano. Os números apresentados na tabela são preocupantes,pois representa que apenasuma pequena parcela de empresas protocolou pedidos de processos de anexo $\mathrm{X}$ perante a Vigilância Sanitária do Município de
Uberlândia (MG), em um universo de 223industrias de pequeno e grande porte cadastradas no município de Uberlândia, MG até o ano de 2016.

O índice de aprovação dos processos pelo setor no período analisado foi muito baixo em relação ao número de processos recebidos e analisados. O ano de 2012 registrou maior número de processos recebidos pelo setor, causado pelo aumento da lista de produtos dispensados de registro conforme a RDC $n^{\circ} 27 / 2010^{[16]}$. O número de processos avaliados foi bem abaixo do número de processos protocolados no setor até o ano de 2015, ocasionando um atraso na avaliação e regulamentação desses processos. A partir de 2016, foram realizadas mudanças no setor de análise, com o aumento provisório do número de analistas de processos, passando de um para dois avaliadores, o que possibilitou um aumento nos processos analisados no setor.

Quanto aos processos aprovados, o ano que obteve maior número de processos aprovados foi em 2014. Nos anos de 2015 e 2016, nenhuma empresa conseguiu realizar as adequações necessárias para a aprovação de seus processos de Comunicação de Início de Fabricação de Produtos Dispensados de Registro.

Nos anos de 2012 a 2016, dentre os processos analisados, 169 (64,5\%) apresentaram todos os documentos nos processos de anexo $\mathrm{X}$ e $60(35,5 \%)$ processos apresentaram a documentação incompleta. Quanto à análise da documentação dos processos de comunicação de início de fabricação dos produtos dispensados de registro, dentre os anos de 2012 a 2015, a não apresentação de algum documento obrigatório no processo era indicada no parecer técnico somente como documentação faltante, não especificando qual documento não estava presente no processo. Neste período, dos 98 processos analisados, 
somente $6(6,12 \%)$ não apresentaram alguma documentação obrigatória.

A apresentação de toda documentação é de suma importância, pois através desta que a empresa comprova se o local de produção do produto comunicado é adequado, se o produtor de embalagens é regulamentado e comunicou o início de fabricação de seu produto e se sua embalagem/rótulo atende ou não a legislação.

$\mathrm{Na}$ Figura 2, podem ser visualizados os percentuais dos documentos que não foram apresentados pelas empresas no ano de 2016, segundo os processos analisados.

Tabela 2. Percentual de documentos faltantes nos processos de anexo $\mathrm{X}$ protocolados pelas empresas na Vigilância Sanitária de Uberlândia, MG, no ano de $2016(\mathrm{n}=71)$.

\begin{tabular}{lc}
\hline \multicolumn{1}{c}{ Documento } & $\begin{array}{c}\text { \% de não } \\
\text { apresentação }\end{array}$ \\
\hline Cópia do alvará sanitário & 73,2 \\
Formulário de comunicação & 53,5 \\
aprovado da embalagem & 15,5 \\
Rótulos & 14,1 \\
Formulário de comunicação & \\
de Início de fabricação de & \\
produtos dispensados de \\
Registro
\end{tabular}

O documento que obteve maior índice de não apresentação nos processos de início de fabricação de produtos dispensados de registro foi o alvará sanitário das empresas (Figura 2). O Alvará ou licença sanitária é o documento expedido pelo órgão municipal de vigilância sanitária atestando que o estabelecimento possui condições física-higiênico estruturais, operativas sanitárias determinadas no código municipal de saúde de Uberlândia e demais legislações pertinentes. A expedição de alvará sanitário é o documento utilizado pela Vigilância Sanitária Municipal de Uberlândia para licenciar as empresas do município quanto às atividades de competência de fiscalização desse órgão ${ }^{[17]}$.

A apresentação desta documentação é de suma importância para a aprovação do processo, pois a realização da aprovação do início de fabricação/produção de produtos comunicados pode ocorrer mediante a aprovação dos locais (da estrutura e das condições higiene do local) pela autoridade sanitária competente. A maioria das empresas apresentou no lugar deste documento o protocolo de entrada do alvará sanitário, o que não vale como comprovação da aprovação do local.

O Formulário de comunicação de início de fabricação dos produtos dispensados de registro (Anexo X) do produtor da embalagem é o documento que os responsáveis pela empresa enfrentam maiores dificuldades na obtenção. Apesar da RDC n²7/2010 ser uma legislação válida para todo o território nacional, a maioria dos estados desconhece a obrigatoriedade da comunicação do início de fabricação dos produtos mencionados nesta legislação. Por isso, quando as empresas de Uberlândia solicitam essa documentação de seus fornecedores, muitos não fazem ideia do que se trata essa documentação, dificultando assim que as empresas apresentem o processo completo $^{[16]}$.

O documento fundamental do processo é o formulário de comunicação de início de fabricação dos produtos dispensados de registro. Conforme define Brasil (2000), a não apresentação do referido formulário torna a comunicação de início de fabricação inválida, pois o formulário é o documento oficial para a realização de tal comunicação ${ }^{[3]}$.

Na Figura 3, estão representados os quantitativos de erros no preenchimento e apresentação dos formulários de comunicação de início de fabricação dos produtos dispensados de registro protocolados pelas 
empresas na Vigilância Sanitária de Uberlândia, MG, nos anos de 2012 a 2016.

Tabela3. Quantitativo de não conformidades no preenchimento e formatação dos formulários de anexo $\mathrm{X}$ protocolados pelas empresas na Vigilância Sanitária de Uberlândia, MG, nos anos de 2012 a $2016(n=169)$.

\begin{tabular}{lc}
\hline \multicolumn{1}{c}{ Formulário } & $\begin{array}{c}\text { \% } \\
\text { conformidade }\end{array}$ \\
\hline $\begin{array}{l}\text { Campo categoria e } \\
\text { descrição da categoria }\end{array}$ & 53,3 \\
Campo tipo de & \\
embalagem & 40,8 \\
Formatação & 23,7 \\
Campo controle de & 20,7 \\
anexo & 20,7 \\
Campo termo de & \\
responsabilidade & 18,9 \\
Campo nome do & \\
produto & 13,6 \\
Campo validade & 3,0 \\
Campo marca do & \\
produto & \\
Campo perspectiva & \\
comercial & 1,4 \\
Campo dados do & \\
detentor da marca & \\
\hline
\end{tabular}

O campo que obteve maior índice de não conformidade nos formulários analisados foi o campo categoria e descrição da categoria. $\mathrm{Na}$ categorização do produto é importante a empresa levar em consideração a finalidade, a composição e a forma de apresentação do produto, além de pesquisar os regulamentos técnicos específicos, que podem ajudar na categorização do produto. A categorização correta do produto é de total responsabilidade do produtor/fabricante.

No campo tipo da embalagem, deve-se declarar o material da embalagem primária e forma de apresentação de comercialização do produto. $\mathrm{O}$ erro mais recorrente foi a não declaração de forma de apresentação de comercialização da embalagem.
O formulário de comunicação de início de fabricação dos produtos dispensados de registro deve ser apresentado no dia que se pretende iniciar a produção $\mathrm{do}(\mathrm{s})$ referido(s) produto(s), conforme modelo apresentado no Anexo X e devem estar impressos no formato frente e verso. Quanto à formatação dos formulários apresentados, os formulários não estavam apresentados em formato frente e verso e/ou não estavam no modelo apresentado na legislação ${ }^{[3]}$.

O campo controle de anexos indica quantas folhas do formulário foram necessárias para comunicar todos os produtos produzidos. O preenchimento adequado deste campo garante a não adulteração do documento, pois o mesmo indica com exatidão as suas quantidades de folhas.

O campo mais importante do formulário é o termo de responsabilidade. Neste campo, a empresa declara a data de início de fabricação e em quantos dias a empresa iniciará a comercialização do produto comunicado, e declara também que conhece as legislações específicas do produto que fabrica (inclusive da rotulagem e outros itens que são pertinentes) e de que está ciente que a autoridade sanitária pode realizar inspeção na unidade fabril conforme Resolução $\mathrm{n}^{\circ} 23$, de 15 de março de $2000^{[3]}$. O não preenchimento correto deste campo torna a comunicação do produto sem valor legal.

Para a comunicação de início de fabricação de produtos, cuja produção é terceirizada (o detentor da marca terceiriza a produção), deve-se preencher o campo dados da unidade fabril com os dados da empresa terceirizada e dados do detentor da marca com os dados da empresa contratante do serviço (que é a detentora da marca). Este item obteve o menor índice de inconformidades nos formulários analisados. A declaração correta destas informações no formulário é importante, pois auxilia na rastreabilidade dos responsáveis 
pela produção, no caso do produto apresentar algum problema de qualidade e/ou risco à saúde do consumidor.

De maneira geral, pôde-se observar que há uma grande porcentagem de não conformidades no preenchimento do formulário de comunicação de início de fabricação de produtos dispensados de registro e na apresentação da documentação pertinente ao processo, evidenciando os motivos do baixo índice de aprovação desses processos. $\mathrm{Na}$ própria legislação que institui a apresentação do formulário para a categoria de produtos dispensados de registro, há um quadro explicativo de como deve ser preenchido tal formulário, porém as empresas não compreendem adequadamente a legislação, resultando em preenchimento incorreto dos formulários e a não legalização de seus produtos.

Os principais erros relacionados às informações obrigatórias nos rótulos no ano de 2012 a 2016 estão indicados na Figura 4. Dentre as categorias de rótulos de produtos analisados estão: Produtos de panificação prontos para consumo e produtos de panificação congelados, suplementos alimentados, cereais, doces, água mineral, temperos e conservas e salgados a base de milho.

Grande parte dos rótulos analisados não continha um ou mais itens de informações obrigatórias (denominação de venda, lista de ingredientes, dados do produtor, data de validade, lote, etc). Problema similar foi encontrado em rótulos de suplementos proteicos $^{[18]}$. Este resultado é preocupante, pois isso demonstra que a maior parte dos produtos produzidos no município e disponibilizados aos consumidores estão não conformes. Como as embalagens são veículos de comunicação entre o produtor e o consumidor, informações incorretas podem gerar menor confiabilidade relativa ao produto comercializado ${ }^{[19]}$.
Tabela 4. Principais não conformidades nas informações obrigatórias dos rótulos apresentados nos processos de anexo $\mathrm{X}$ protocolados pelas empresas na Vigilância Sanitária de Uberlândia, MG, nos anos de 2012 a $2016(n=169)$.

\begin{tabular}{lc}
\hline \multicolumn{1}{c}{ Rotulagem } & $\begin{array}{c}\text { \% de não } \\
\text { conformidade }\end{array}$ \\
\hline Não apresentação de todas as & 97,6 \\
informações obrigatórias & \\
Lista de ingredientes & 68,6 \\
Conteúdo líquido & 67,5 \\
Informações Gerais & 59,1 \\
Validade & 54,4 \\
Denominação de venda & 53,8 \\
Identificação de origem & 44,4 \\
Lote & 44,4 \\
Apresentação e distribuição da & 39,0 \\
informação & \\
Aditivos & 25,4 \\
Condições de conservação & 13,0 \\
Instrução de preparo e uso & 5,9 \\
\hline
\end{tabular}

$\mathrm{Na}$ lista de ingredientes devem ser informados todos os ingredientes contidos no produto e deve ser precedida pelas expressões "ingredientes:" ou "ingr.:". Dentre os itens não conformes neste item, constatou-se a ausência de lista de ingredientes, a declaração dos itens não obedecendo à ordem decrescente e a ausência de declaração de farinha de trigo seguida da frase "fortificada ou enriquecida ou rica em ferro e ácido fólico".

O conteúdo líquido deve ser informado em tamanho de letra determinado em legislação específica de acordo com o tamanho de comercialização do produto. Esse foi a maior não conformidade encontrada nos rótulos analisados. A ausência dessa informação foi verificada em alimentos diet e light ${ }^{[20]}$, biscoitos $^{[21]}$ e produtos caseiros de panificação $^{[22]}$.

As informações gerais consistem em qualquer imagem ou dizeres contidos nos rótulos. Entre os erros mais comuns contidos 
nos rótulos analisados estavam a utilização de figuras no rótulo que podiam induzir o consumidor ao erro quanto ao alimento e expressões quanto a denominações de qualidade que não podem ser comprovadas. Problemas nas informações gerais dos rótulos de alimentos também foram encontrados em barras de cereais ${ }^{[23]}$, alimentos consumidos em escolas $^{[24]}$ e água mineral ${ }^{[25]}$.

Dentre as não conformidades mais frequentes na avaliação do item data de validade, estavam a ausência da informação no rótulo e a utilização de dias de validade ao invés da data exata de validade. Problemas similares foram encontrados na avaliação do rótulo de alimentos destinados para o público infantil ${ }^{[26]} \mathrm{e}$ para pães e bolos ${ }^{[21]}$. Segundo Gonçalves et al. ${ }^{[27]}$, a informação da rotulagem dos alimentos mais importante para os consumidores da cidade de São Vicente (SP) é a data de validade.

A ausência de data de validade ou declaração deste item contrariando a legislação é preocupante. $\mathrm{Na}$ hipótese do alimento ser adquirido com o prazo de validade expirado, existem altas possibilidades de perder propriedades nutricionais e sensoriais, além de ser possível veículo de Doenças Transmitidas por Alimentos (DTAs) ao consumidor ${ }^{[28]}$.

A denominação de venda obteve alto índice de não conformidade nos rótulos avaliados e os erros com maior incidência nos rótulos eram a não utilização de denominações de venda definidos pelos Regulamentos Técnicos do produto e a não utilização de palavras adicionais nesta denominação para definição de sabor e condições físicas do produto, como colocar congelado junto à denominação de venda, conforme preconizado por Brasil ${ }^{[13]}$. Na literatura, os rótulos de néctares de frutas ${ }^{[29]}$, pães e biscoitos ${ }^{[21]}$ não declararam adequadamente a denominação de venda. $O$ alto índice de não conformidade encontrado neste item evidencia que as empresas não estão comunicando adequadamente o consumidor o que está sendo adquirido.

$\mathrm{Na}$ avaliação da declaração de origem, os maiores índices de não conformidade encontrados foi a não declaração dos dados completos do produto e ausência de expressão que deve preceder essas informações. Estudos que analisaram os rótulos de alimentos à base de cereais para alimentos infantis ${ }^{[30]}$ e água mineral ${ }^{[25]}$ encontraram os mesmos problemas.

A ausência da identificação de origem nesses produtos indica que produtos dessa natureza estão sendo fornecidos à população sem conhecimento do local onde são fabricados, deixando dúvidas sobre as condições sanitárias em que são produzidos e, consequentemente, se os mesmos têm qualidade ${ }^{[21]}$.

A identificação de lote é utilizada pela indústria como forma de monitorar o produto, podendo retirá-lo de comercialização quando for necessário ${ }^{[31]}$. O maior problema encontrado nos rótulos analisados foi a ausência da declaração desta informação no rótulo. $\mathrm{Na}$ avaliação de pães e biscoitos ${ }^{[21]}$, pães, barras de cereais $^{[32]}$ e biscoitos recheados sabor chocolate $^{[28]}$ foram encontrados resultados equivalentes.

No item apresentação e distribuição da informação, a maior incidência de não conformidades encontradas foi o tamanho da letra das informações obrigatórias.

Como parte integrante da lista de ingredientes, os aditivos devem ser declarados com descrição de sua função e nome ou INS do aditivo. Dentre os erros mais comuns nos rótulos analisados quanto aos aditivos, estavam a declaração misturada com os ingredientes na lista de ingredientes e ausência de declaração da função ou INS/nome do aditivo. Em alimentos consumidos em escolas ${ }^{[24]}$ também foi verificada não conformidades na declaração de aditivos. 
As instruções de conservação declaradas nos rótulos dos alimentos têm por objetivo instruir o consumidor de como realizar $\mathrm{O}$ armazenamento antes e depois da abertura dos produtos, indicando as precauções necessárias para manter suas características normais ${ }^{[33]}$. Em estudo realizado sobre o macarrão instantâneo ${ }^{[24]}$ e rótulos de biscoitos recheados sabor chocolate ${ }^{[28]}$ foram encontrados não conformidades nesse item.

Quanto a instruções de uso e preparo, a maior incidência de erros neste item foi apresentação da informação confusa. A adequada orientação de uso e preparo do alimento ao consumidor é importante para eliminar possíveis riscos a saúde do consumidor e proporciona-lo a melhor experiência sensorial no consumo deste alimento. Nos rótulos avaliados, este item apresentou o menor índice de não conformidades.

Além das legislações básicas que regulamentam os itens obrigatórios para todos os alimentos, existem legislações que regulamentam itens obrigatórios nos rótulos dos alimentos por categoria. Na Figura 5, são apresentadas as principais não conformidades relacionadas às informações nutricionais $\mathrm{e}$ legislações específicas dos rótulos apresentados nos processos de comunicação de início de fabricação de alimentos isentos de registro protocolados pelas empresas na Vigilância Sanitária de Uberlândia, MG, nos anos de 2012 a 2016.

Neste estudo, os rótulos analisados apresentaram tabelas nutricionais com erros em formatação, na declaração dos valores diários e na apresentação das unidades e expressões dos valores energéticos e nutrientes, cujas regras são definidas em legislação ${ }^{[9]}$.
Tabela 5. Quantitativo de não conformidades relacionadas às informações nutricionais e legislações específicas dos rótulos apresentados nos processos de anexo $\mathrm{X}$ protocolados pelas empresas na Vigilância Sanitária de Uberlândia, MG, nos anos de 2012 a 2016 ( $\mathrm{n}=169)$.

\begin{tabular}{lc}
\hline \multicolumn{1}{c}{ Rotulagem } & $\begin{array}{c}\% \text { não } \\
\text { conformidade }\end{array}$ \\
\hline Informação Nutricional & 81,7 \\
Alergênicos* & 53,7 \\
Intolerantes & 33,1 \\
Informação Nutricional & 10,1 \\
complementar & \\
Denominação de & 4,1 \\
qualidade & \\
Suplementos para atletas & 1,2 \\
Cereais embalados & 1,2 \\
Compostos Líquidos & 0,6 \\
\hline * Avaliado somente nos anos de 2015 e 2016.
\end{tabular}

A rotulagem nutricional tem sido destacada e valorizada pelas pesquisas e pelos consumidores, devido ao seu papel importante como facilitador de escolhas mais saudáveis, uma vez que o rótulo é o principal veículo de comunicação entre os consumidores e a indústria $^{[32]}$. Os rótulos de produtos de panificação ${ }^{[22]}$ e geleias de uvas ${ }^{[34]}$ apresentaram problemas similares.

Dentre os problemas encontrados nos rótulos analisados estavam o cálculo do valor diário e a declaração de porção e medida, itens obrigatórios na tabela nutricional. $\mathrm{Na}$ avaliação da rotulagem de maionese, margarina e néctar de frutas ${ }^{[29]}$ apresentaram problemas similares na declaração do valor diário. A declaração de porção e medida caseira é importante, pois auxilia $O$ consumidor na avaliação $d a$ quantidade de nutrientes e valor energético que está sendo consumido do alimento. Problemas na declaração de porção e medida caseira também foram verificados em doces $\operatorname{diet}^{[28]} \mathrm{e}$ maionese, néctares e margarinas ${ }^{[27]}$. 
Processos de Anexo X em vigilância sanitária de Uberlândia. Oliveira et al.

Os resultados obtidos nos itens avaliados na rotulagem nutricional nesta pesquisa são alarmantes, pois apresentaram altos índices de não conformidades. A apresentação desta informação em atendimento à legislação é essencial para o consumidor ter acesso às informações nutricionais do alimento, e a partir dessas informações fazer escolhas alimentares mais saudáveis e facilitar o trabalho dos profissionais da área de nutrição ${ }^{[35]}$.

A legislação que regulamenta a declaração de alimentos alergênicos foi instituída no dia 2 de julho de 2015 e as empresas tiveram um ano para adequação de seus rótulos. Portanto, a exigência quanto a essa adequação foi iniciada na metade do ano de 2015 (em forma de orientação de que a empresa deveria realizar esta adequação em um ano) e a partir de 2016, em que as empresas foram notificadas a colocarem a informação no rótulo.

Dentre as não conformidades encontradas referentes a esse item estão a declaração não utilizando as palavras determinadas na legislação e o não destaque desta informação conforme preconiza a referida legislação. $\mathrm{Na}$ avaliação de produtos lácteos ${ }^{[36]}$ foram verificadas a ausência desta informação. A declaração de alergênicos clara e legível no rótulo é importantepara que os consumidores com alergia identifiquem a presença de componentes causadores de complicações clinicas e assim evitar seu consumo ${ }^{[37]}$.

A síndrome celíaca, doença hereditária onde o indivíduo possui intolerância ao glúten, causa uma inflamação na parede do intestino causando uma má absorção de nutriente como gorduras, vitaminas e minerais pelo organismo [21]. A lei n 10.674/2003 impõe a identificação no rótulo do produto quanto à presença ou não do glúten com o objetivo de advertir, prevenir e tentar controlar a doença celíaca, que afeta boa parte da população brasileira ${ }^{[28]}$.
Nos rótulos avaliados apresentavam não conformidades relacionadas à ausência da informação de presença ou não de glúten ou a presença dessa informação sem estar em destaque, nítida e de fácil leitura. Em rótulos de alimentos destinados ao público infantil ${ }^{[26]} \mathrm{e}$ doces diet ${ }^{[38]}$ apresentavam problemas neste item.

A informação nutricional complementar (INC) é regulamentada pela RDC n54/2012, definida como uma informação utilizada para descrever o nível absoluto ou relativo de determinados nutrientes ou valor energético presentes em alimentos ${ }^{[39]}$, sendo uma declaração opcional para a empresa.

Problemas na INC também foram encontrados no estudo de alimentos com alegações de propriedades nutricionais ${ }^{[40]}$. Alegações de INC realizadas em rótulos de alimentos que não possuem tais propriedades podem levar o consumidor a consumir produtos que podem afetar de forma grave sua saúde.

$\mathrm{Na}$ avaliação da denominação de qualidade, afirmações de "mais gostoso", "o melhor da cidade" e "caseiro" levar o consumidor a não entender corretamente a informação tendo em vista que essas afirmações variam de pessoa para pessoa além de não possuírem definições determinadas pela legislação. Denominações de qualidade que contrariam a legislação podem induzir o consumidor ao erro, levando-o a achar que está consumindo produtos com características que o mesmo não possua.

Os produtos classificados em categorias específicas apresentaram menores índices de não conformidades. Dentre as 169 empresas avaliadas, duas apresentaram não conformidades relacionadas a cereais embalados, uma quanto à legislação de compostos líquidos e duas quanto à legislação de suplementos para atletas. Essa menor 
porcentagem de não conformidades pode ser devida ao número reduzido de rótulos enquadrados nas categorias de alimentos específicos.

Assim como observado nos documentos apresentados nos processos de comunicação de início de fabricação de produtos dispensados de registro e no preenchimento dos formulários na Vigilância Sanitária de Uberlândia, foram encontrados um alto índice de não conformidades na rotulagem dos produtos comunicados dificultando a aprovação desses processos. Pode-se perceber que o setor regulado possui muitas dificuldades na elaboração dos processos e da rotulagem dos produtos, sendo necessárias ações educativas para melhorar o conhecimento acerca destes processos. $\mathrm{O}$ principal risco da não regulamentação é a exposição aos consumidores de produtos com rótulos não fidedignos.

Os processos de produtos dispensados de registro (processos de anexo $\mathrm{X}$ ), responsabilidade da Vigilância Sanitária dos municípios, não são comumente cobrados das empresas, provavelmente por falhas de fiscalizaçãoe desconhecimento da legislação por parte dos técnicos responsáveis. Estesempecilhos podem justificar a escassez de literatura disponível que aborda a legislação aplicada aos produtos dispensados de registro, tendo em vista que os procedimentos de regulação desta categoria de produto deveriam ser práticas rotineiras nos órgãos fiscalizadores. As ações educativas devem também ser estendidas aos agentes das Vigilâncias Sanitárias municipais para que os processos sejam efetivamente cobrados das empresas e que os mesmos alcancem maiores índices de aprovação.

Além de ações educativas, é importante a melhoria da estrutura do setor de análise dos processos de anexo $\mathrm{X}$ para a realização da avaliação dos processos e a disponibilização de mais funcionários para realizar a avaliação de tais processos.

\section{CONCLUSÃO}

Foram diagnosticados altos índices de não conformidades nos rótulos e nos processos de Anexo X no âmbito da Vigilância Sanitária de Uberlândia, MG, justificando a dificuldade que o setor regulado possui em adequar essa documentação. $\mathrm{O}$ desconhecimento da legislação e falhas estruturais da Vigilância Sanitária contribuem para esta realidade.

Medidas educativas, como a disponibilização de apoio técnico, confecção de cartilhas e realização de minicursos sobre o tema são importantes para instrução das empresas e agentes da vigilância quanto à montagem e a elaboração correta dos processos de comunicação de início de fabricação de produtos dispensados de registro. Outra necessidade é a reestruturação dos órgãos fiscalizadores para que tenham condições de exercerem seus papéis de vigilantes da saúde e promotores do bem-estar da população.

\section{AGRADECIMENTOS}

À Fapemig pelo apoio financeiro e à Vigilância Sanitária de Uberlândia pelo apoio técnico para a realização desta pesquisa.

\section{REFERÊNCIAS}

[1] Abe-Matsumoto LT, Sampaio GR, Bastos, DHM. Suplementos vitamínicos e/ou minerais: regulamentação, consumo e implicações à saúde. Caderno Saúde Pública. 2015; 31(7): 1371-80.

[2] Vigilância Sanitária de Uberlândia Instruções gerais para a montagem do processo de comunicação de início de Fabricação Anexo X, rotulagem e embalagens [internet]. 
Uberlândia; 2014. [acesso em 06 maio 2017]. Disponível em:

http://www.uberlandia.mg.gov.br.

[3] Brasil. Resolução no 23, de 15 de março de 2000. Dispõe sobre O Manual de Procedimentos Básicos para Registro e Dispensa da Obrigatoriedade de Registro de Produtos Pertinentes à Área de Alimentos. Diário Oficial da União. 16 mar. 2000.

[4] Antunes F, Nogari F, Martins PR da R, Lyng SOM. Avaliação de dizeres de rotulagem para produtos fabricados no município de Curitiba. Gestão Pública em Curitiba, 2010; $1(2): 4-6$.

[5] Brasil. Lei $n^{\circ}$ 8.078, de 11 de setembro de 1990. Dispõe sobre a proteção do consumidor e dá outras providências. Diário Oficial da União. 12 set 1990 .

[6] Brasil. Resolução RDC n 259, de 20 de setembro de 2002. Dispõe sobre a rotulagem geral de alimentos embalados. Diário Oficial da União. 23 set 2002 .

[7] Brasil. Resolução RDC n 26, de 02 de julho de 2015. Dispõe sobre a rotulagem obrigatória dos principais alimentos que causam alergias alimentares. Diário Oficial da União. 3 jul 2015.

[8] Brasil. Lei n 10.674 , de 16 de maio de 2003. Dispõe sobre a obrigatoriedade nos produtos alimentícios comercializados informem sobre a presença de glúten, como medida preventiva e de controle de doença celíaca. Diário Oficial da União. 19 maio 2003.

[9] Brasil. Resolução RDC n ${ }^{\circ} 360$, de 23 de dezembro de 2003. Dispõe sobre a obrigatoriedade da rotulagem nutricional. Diário Oficial da União. 26 dez 2003.

[10] Brasil. Portaria $n^{\circ} 29$, de 13 de janeiro de 1998. Dispõe sobre regulamento técnico referente a alimentos para fins especiais. Diário Oficial da União. 30 mar 1998.

[11] Brasil. Portaria $n^{\circ} 32$, de 13 de janeiro de 1998. Dispõe sobre o regulamento técnico para suplementos vitamínico e/ou minerais. Diário Oficial da União. 15 de jan 1998.

[12] Brasil. Decreto $n^{\circ} 4.680$, de 24 de abril de 2003. Dispõe sobre a regulamentação do direito à informação quanto aos alimentos e ingredientes alimentares destinados ao consumo humano ou animal que contenham ou sejam produzidos a partir de organismos geneticamente modificados, sem prejuízo do cumprimento das demais normas aplicáveis. Diário Oficial da União. 28 abr 2003.

[13] Brasil. Resolução RDC n²73, de 22 de setembro de 2005. Dispõe sobre o regulamento técnico para misturas para o preparo de alimentos e alimentos prontos para o consumo. Diário Oficial da União. 23 set 2005.

[14] Brasil. Instrução Normativa n ${ }^{\circ} 12$, de 28 de março de 2008. Dispões sobre o Regulamento técnico do feijão, definindo o seu padrão oficial de classificação, com os requisitos de identidade e qualidade, a amostragem, o modo de apresentação e a marcação ou rotulagem. Diário Oficial da União. 31 mar 2008.

[15] Brasil. Instrução Normativa $n^{\circ} 06$, de 18 de fevereiro de 2009. Dispõe sobre o Regulamento técnico do arroz, definindo seu padrão oficial de classificação, com requisitos de identidade, qualidade, a amostragem, o modo de apresentação e a marcação ou rotulagem. Diário Oficial da União. 18 fev 2009.

[16] Brasil. Resolução RDC $n^{\circ} 27$, de 6 de agosto de 2010. Dispõe sobre as categorias de alimentos e embalagens isentos e com obrigatoriedade de registro sanitário. Diário Oficial da União. 22 maio 2010. 
[17] Uberlândia. Lei nº10.715, de 21 de março de 2011. Institui o código municipal de saúde. Diário Oficial do Município, 22 mar 2011.

[18] Freitas HR, Bizarello TB, Romano US, Santana B da S, Haubrich R, Castro IPL. de. Avaliação da rotulagem e informação nutricional de suplementos proteicos impostados no Brasil. Revista Brasileira de Nutrição Esportiva. 2015; 9(49):14-24.

[19] Bronzatto MJ, Goulart JQ, Ferreira JI., Pinto AT. Análise da adequação de rotulagem de ovos de postura comercial comercializados no município de Itajai/SC. In: livro de resumos do XL Congresso Brasileiro de Medicina Veterinária; 20137 - 10 agosto; Salvador, Bahia: CONBRAVET: 2013.p. 49.

[20] Barros TSG, Carvalho D, Córdova S, Sales L, Cardoso V, Moreira APB. Avaliação dos rótulos de alimentos doces e light. In: livro de resumos VIII Simpósio de produção Acadêmica; 201620 outubro; Viçosa, Minas Gerais: SIMPAC: 2016. p. 259-62.

[21] Gonçalves I da S. Análise de rótulo de pães e biscoitos produzidos por pequenas e medias industrias das regiões do recôncavo e sudoeste da Bahia e comercializados em Cruz das AlmasBA. [dissertação]. Salvador: Universidade Federal da Bahia; 2012. 60 p.

[22] Pedroso TC. Análise dos rótulos de produtos caseiros de panificação. [trabalho de conclusão de curso]. Pindamonhangaba: Faculdade de Pindamonhangaba, 2012. 55 p.

[23] Silva AS, Lorenzo ND, Santos OV. dos. Comparação dos parâmetros de rotulagem e composição nutricional de barras proteicas. Revista Brasileira de Nutrição Esportiva. 2016; 10(57):350-60.

[24] Garcia MR. Conformidade da rotulagem de alimento consumidos por escolares à legislação brasileira [dissertação]. Botucatu: Universidade
Estatual Paulista "Júlio de Mesquita Filho"; 2012. 77 p.

[25] Borges RG, Conrado ALV, Assis L de, Ribeiro C da SG. Rotulagem de água mineral engarrafada: avaliação de conformidades às legislações nacional e do Mercosul. InterfacEHS - Saúde, meio ambiente e sustentabilidade. 2016; 11(2):61-79.

[26] Mello AV de, Abreu ES de, Spinelli MGN. Avaliação de rótulos de alimentos destinados ao público infantil de acordo com as regulamentações da legislação brasileira. Journal of the health sciences Institute. 2015; 33(4): 351-59.

[27] Gonçalves NA,Cecchi PP, Vieira RM, Santos MDA dos, Almeida TC de. Rotulagem de alimentos e consumidor. Nutrição Brasil. 2015; 14(4).

[28] Feitosa BF, Neto JO de O, Oliveira ENA de, Feitosa JVF, Feitosa RM, Junior LAMD. Avaliação da rotulagem de diferentes marcas de biscoitos recheados sabor chocolate comercializados em Pau do Ferros - RN. Revista A Barriguda. 2016; 6(2): 230-41.

[29] Carneiro AP de G, Abreu DA, Soares DJ, Costa E de A, Silva LMR da; Barbosa LC, Sousa PHM de, Figueiredo RW de. Avaliação da rotulagem, caracterização química, físicoquímica e reológica de néctares de uva comercializados na cidade de Fortaleza - CE. Alimentos e Nutrição $=$ Brazilian Journal of Food and Nutrition. 2013; 24(2): 241-49.

[30] Brito LF, Silva A de PV da, Mendes LG, Medeiros SRA. Avaliação da rotulagem de alimentos à base de cereais para a alimentação de lactentes e crianças da primeira infância. Demetra: Alimentação, nutrição \& saúde. 2016; 11(1): 111-20.

[31] Silva TM. Avaliação do mel industrial comercializado em supermercados da cidade de 
Formiga-MG. [Trabalho de Conclusão de Curso]. Formiga: Centro Universitário de Formiga-MG, 2016. 28p.

[32] Pereira JRP, Nomelini QSS, Pascoal GB. Análise de conformidades das informações apresentadas nos rótulos de barras de cereais e pães light. Revista Cientifica Linkania Master. 2014; 1(9): 137-55.

[33] Torquato VS da A, Occhioni CV de O, Sousa, MRP de. Avaliação da rotulagem de leites UAT comercializados por estabelecimentos varejistas no município do Rio de Janeiro - RJ, Brasil. Veterinária Notícias. 2016; 22(2):19-23.

[34] Carvalho S. dos S. Avaliação da adequação de rotulagem nutricional para margarinas, maioneses e néctar de frutas. [trabalho de conclusão de curso]. Campo do Mourão: Universidade Tecnológica Federal do Paraná, 2014. 58 p.

[35] Camara FA, Weschenfelder S. Leite UHT integral: Avaliação da rotulagem nutricional e dos padrões de identidade e qualidade. Revista Instituto Laticínios Cândido Tostes. 2014; 69(4):268-79.

[36] Piletti R, Freitas AR. Analise da rotulagem de produtos lácteos de diferentes marcas de acordo com a legislação RDC $\mathrm{n}^{\circ} 26$, de 02 de julho de 2015. Revista Ciências Agroveterinárias e Alimentos. 2016 [Acesso em: 01 abr. 2017]; 1. Disponível em: http://revista.faifaculdades.edu.br:8080/.

[37] Criollo LFR. Monitoramento e avaliação da regulamentação sobre rotulagem alergênicos no Brasil: proporção de indicadores e métricas. [dissertação]. Rio de Janeiro: Pontifica Universidade católica do Rio de Janeiro, 2016. $116 \mathrm{p}$.

[38] Mello TCV de, Pascoal GB. Análise Crítica de rotulagem de doces diet e alimentos com alegações de propriedades funcionais e/ou de saúde. Revista cientifica Linkania máster. 2014 [Acesso em: 19 abr. 2017]; 1(8):42-58. Disponível em: http://linkania.org/master.

[39] Anvisa - Apresenta perguntas e respostas sobre a Informação Nutricional complementar [internet]. Brasília; 2013. [acesso em 22 mar 2017]. Disponível em: http://portal.anvisa.gov.br/.

[40] Freitas MR. Avaliação da adequação de rotulagem para os alimentos com alegação de propriedade funcional: fibras alimentares. [Trabalho de conclusão de curso]. Brasília: Universidade de Brasília, Brasília, 2014. 58 p. 